Portland State University

PDXScholar

1977

\title{
The Development of a Patient Satisfaction Evaluation System in a Family Practice Setting
}

Lynda Ater

Portland State University

Follow this and additional works at: https://pdxscholar.library.pdx.edu/open_access_etds

Part of the Health and Medical Administration Commons, and the Medical Education Commons Let us know how access to this document benefits you.

\section{Recommended Citation}

Ater, Lynda, "The Development of a Patient Satisfaction Evaluation System in a Family Practice Setting" (1977). Dissertations and Theses. Paper 2118.

https://doi.org/10.15760/etd.2116

This Thesis is brought to you for free and open access. It has been accepted for inclusion in Dissertations and Theses by an authorized administrator of PDXScholar. Please contact us if we can make this document more accessible: pdxscholar@pdx.edu. 
THE DEVELOPMENT OF A

PATIENT SATISFACTION EVALUATION SYSTEM

IN A FAMILY PRACTICE SETTING

\author{
by \\ LYNDA ATER \\ A practicum submitted in partial fulfillment of the \\ requirements for the degree of
}

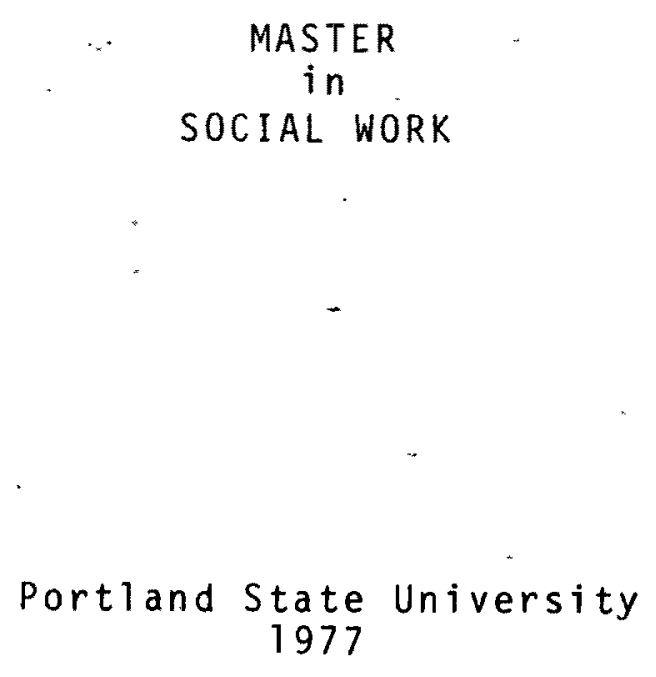


TO THE OFFICE OF GRADUATE. STUDIES AND RESEARCH:

APPROVED :

Quentin D. Clarkson, Associate Professor, School of Social Work 


\section{TABLE OF CONTENTS}

PAGE

ACKNOWLEDGMENTS. . . . . . . . . . . . . . . . . . vi

LIST OF TABLES : . . . . . . . . . . . . . . . . . . . vi

I INTRODUCTION. . . . . . . . . . . . . . . . 1

I I LITERATURE REVIEW . . . . . . . . . . . . . . . . .

Patient Satisfaction with Primary

Care: Instrument Development

and Surveys

Implications of Patient Satisfaction

for Academic Medicine and Administra-

tive Policy

I I I METHOD. . . . . . . . . . . . . . . . . . . . 7

Conceptualization of Sampling

Scheme

Questionnaire Development

Pilot Study

IV FINDINGS. . . . . . . . . . . . . . . . 18

Goal Attainment

Factor Analysis

$\checkmark$ CONCLUSION AND RECOMMENDATIONS. . . . . . 27

Questionnaire

Sampling Scheme

Additional Considerations

SELECTED BIBLIOGRAPHY. . . . . . . . . . . . . . . . . 34

APPENDIX A . . . . . . . . . . . . . . . . . . 36

APPENDIX B . . . . . . . . . . . . . . . . . . . . . . . . 49 
$\vee i$

\section{ACKNOWLEDGEMENTS}

First of all, I wish to acknowledge my debt to, the faculty, residents, and staff at the Family Practice Center for their suggestions, cooperation, and encouragement in the development of this patient satisfaction evaluation system.

I also want to express my appreciation for the assistance I have received from Dr. Deane Clarkson and Mr. Brian Hines. Their reactions and thoughtful criticisms contributed much to this project.

I am particularly grateful to Ms. Linda Sharek who carefully typed the final manuscript. 


\section{LIST. OF. TABLES}

TABLE

PAGE

1 Quality Control in Industry and in a Health Setting. . . . . . . . . . 9

2 Partial Demographic Characteristics of the Respondents. . . . . . . 15

3 Frequencies, Percentages, and Goal Attainment of Entire Family Practice Clinic........... . . 19

4 Factor Structure of the Questionnaire. : . 25 


\section{INTRODUCTION}

Patient satisfaction and dissatisfaction are being increasingly recognized as important dimensions of quality medical care. The evaluative literature in the health field reflects this recognition by listing dissatisfaction as an outcome of care along with death, disease, disability, and discomfort (Berkanovic and Marcus, 1976). Further, with the introduction of a National Health "Insurance and the subsequent removal of many barriers to the utilization of services, consumer perceptions of providers and service characteristics may play a more important role in determining what people do. Pleas have also been made by health service researchers to include in medical education programs the objective of preparing professionals to meet consumers' needs so that they (the professionals) can better function in new health care. delivery systems (McGuire, 1973).

The subject of this paper is the development and use of a patient satisfaction evaluation system in a family practice setting. The impetus for the project came from an expressed desire by Department of Family Practice personnel at the University of Oregon Health Sciences Center to" continuously evaluate patient satisfaction at their clinic, the Family Practice Center. They wanted a system that would interfere minimally with the delivery of care while simultaneously disclosing sources of patient satisfaction and dissatisfaction. 
The information would be used to improve those aspects. of patient care and service delivery that could be administratively manipulated. Because the clinic acts as a training center for family practice residents, the system would also. be used as a teaching tool affording patient satisfaction feedback to individual residents. Patients, too, would routinely receive reports of the results.

More specifically, Family Practice Department personnel desired the following: (1) a short questionnaire to be administered at the site of care; (2) a suitable sampling scheme-one that would provide routine feedback on patient satisfaction and dissatisfaction to the residents and to the family Practice Center as a whole; and (3) methods for conducting efficient analyses and routine reporting of the data.

This paper addresses the developmental aspect of the system described above as well as the initial results gained from piloting it. Because a pilot study is by definition a trial-and-error phase, an attempt will be made in the conclusion and Recommendation section to: (1) answer the basic question, How feasible is the continuous operation of this patient satisfaction evaluation system?; and (2) make recommendations that will hopefully increase the chances of a successful permanent implementation. 


\section{LITERATURE REVIEW}

Literature in the health field is replete with patient satisfaction studies, though few attempt to utilize the results in administrative decision-making processes or medical education programs. None, to my knowledge, address the continuous evaluation of patient satisfaction as a quality control mechanism. An attempt will be made in this brief review to highlight those studies regarding; (1) patient satisfaction with primary care, and (2) the implications of patient satisfaction for administrative policy and academic medicine.

Patient Satisfaction with Primary Care:

Instrument Development and Surveys

Hulka, Zyzanski et al. $(1970,1971,1974,1975)$ have done extensive work around the development of questionnaires and scales that measure patients' attitudes toward physicians and primary medical care. Three distinct elements of medical care are addressed in these instruments; (1) professional competence, (2) personal qualities of the physicians, and (3) cost/convenience. They pretested their questionnaires and scales on general population groups and patient samples, and found that the level of satisfaction differed along each of the previously stated dimensions depending on the characteristics of the respondents and the systems of care utilized. Some factors associated with the patient evaluation of 
health care have been investigated by Linn (1975). He disclosed three independent correlates of patient satisfaction; age, community satisfaction, and the nature and degree of continuity of care characterizing the visit.

Ware and Snyder (1975) have rigorously developed and tested a patient satisfaction questionnaire. Four major dimensions of patient attitudes were identified and described, including attitudes toward doctor conduct and such enabling components as availability of services, continuity/convenience of care and access mechanisms. They found that measures of attitudes toward caring and curing aspects of doctor conduct appear to reflect the same underlying attitudinal dimension.

Kisch and Reeder (1969) weakened the contention held by many physicians that patients are not able to evaluate the performance of physicians. They incidentally found in a study of ambulatory medical care utilization that the patients' appraisal of physician performance was highly correlated with professional criteria for assessing competent professional performance.

An attempt was made by Lebow (1975) to describe and assess an outpatient pediatric practice through the use of consumer questionnaires. Interestingly enough, he discovered no relationship between; (1) length of illness and the rated quality of care received, and (2) illness versus absence of illness and the perceived quality of care.

$$
\text { for Academic Medicine and Administrative Policy }
$$

A useful model for integrating health care research into educational programs has been suggested by McGuire (1973). She 
calls for a health care research program that will both identify the needs of health care consumers and lend assistance in the design of medical education programs that prepare professionals to meet those needs.

Berkanovic and Marcus (1976) acknowledge that consumer satisfaction with health care is a frequently measured variable by health service researchers. Yet they maintain that the relevance of this variable for health policy is not always clear. They subsequently attempted to link levels of satisfaction to both administratively manipulable aspects of the organization under study and subsequent client behavior.

Their data suggest that levels of consumer satisfaction can be manipulated by altering organizational behavior. One weakness in Berkanovic and Marcus' study results from the static quality of their cross-sectional research design. Although they demonstrated the existence of a relationship among perceptions, satisfaction, and organizationally relevant behavior at one moment in time, it remains to be seen whether these perceptions or behavior with respect to the use of services can be changed by changing policy. The Family Practice Department at the University of Oregon Health Sciences Center should be able to strengthen the above mentioned weakness by continuously evaluating patient satisfaction at their clinic.

Hines et a1. (1977), the Family Practice Department's own research evaluation team, last year conceived of a patient satisfaction feedback system that would provide specific information for use in resident training and in the general operation of the clinic. They first tried to explicitly define 
6

what constituted an acceptable level of satisfaction. A questionnaire was subsequently designed and administered, and the results were measured against the predetermined level. Administrative steps are presently being taken to correct the disclosed discrepancies. Upon completion of their study they decided a more sensitive instrument and sampling scheme was needed in order to better achieve their objective. This study is the direct result of a recommendston made by the Family Practice Department's evaluation team. 


\section{METHOD}

\section{As sumptions}

In general, a set of assumptions underlie any research or evaluation endeavor. The following suppositions were taken for granted in developing this patient satisfaction monitoring system.

1. Patients' perceptions are partly rooted in their experiences with seeking and obtaining health care, and these experiences can be controlled administratively.

2. Patients' perceptions about the health care they receive can vary from experience to experience. In order to avoid selective perception and memory loss, these perceptions are more accurately measured immediately upon the receipt of services and on an ongoing basis.

3. Patients are more likely to honestly evaluate medical care within a nonpunitive atmosphere. Continuously evaluating satisfaction and taking action on patient complaints regardless. of how trivial can contribute toward effecting this environment.

\section{Conceptualization of Sampling Scheme}

The conceptual framework for the sampling scheme wa's borrowed from industrial quality control methods. This method can best be understood by first describing it in a production setting and then considering its application to a health clinic. 
Table 1 graphically depicts the quality control mechanism in both settings. There are, of course, some conspicuous differences between a manufacturing process and the medical care process. A manufacturer, for instance, has a great deal of control over the variables that interact with the product as it is processed, largely because the product is an inanimate object. On the other hand, a health care administrator or physician exercises much less control over the variables interacting with the patient as he or she moves through the care process, mostly because these variables are psycho-social in nature and thus ill-defined. Notwithstanding these differences, the two processes are enough alike in certain critical respects to justify use of the same quality control concept in both settings.

A manufacturing plant may be regarded as an operation transforming incoming parts into outgoing products. The manufacturer wants to minimize the number of defective parts coming in and the number of defective products going out. In order to do this, he or she erects a screen at both ends of the manufacturing process. In order to simplify this discussion only the 'outgoing product' end will be addressed. The screen in manufacturing vernacular is called the "Acceptance Sampling Plan" and is composed of the following steps:

1. Set a goal--the number of defective products the manufacturer will tolerate.

2. Take a sample from each batch of products and determine the ACCEPTANCE RANGE in order to account for sampling variation. The ACCEPTANCE RANGE becomes, in effect, the revised goal. 


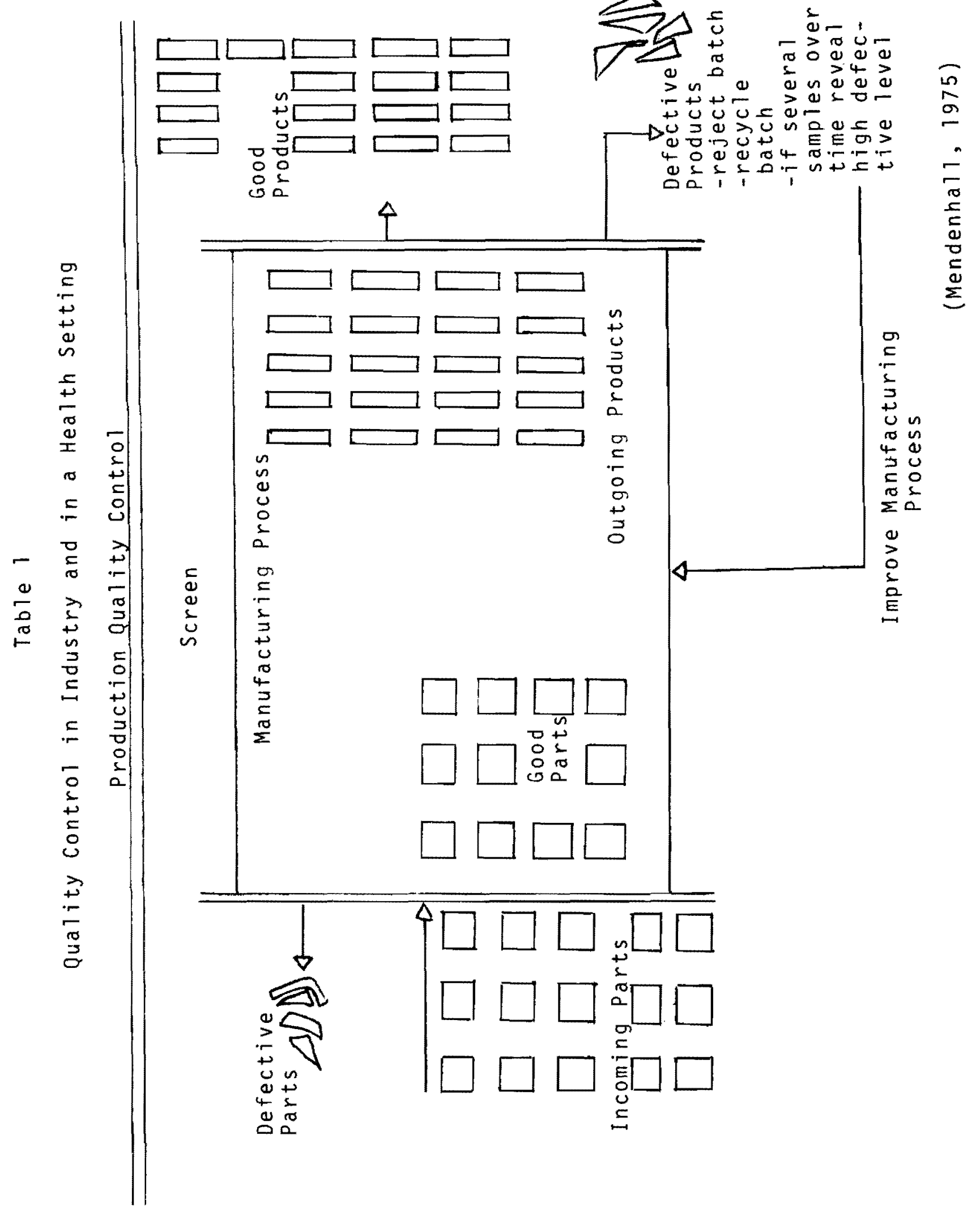




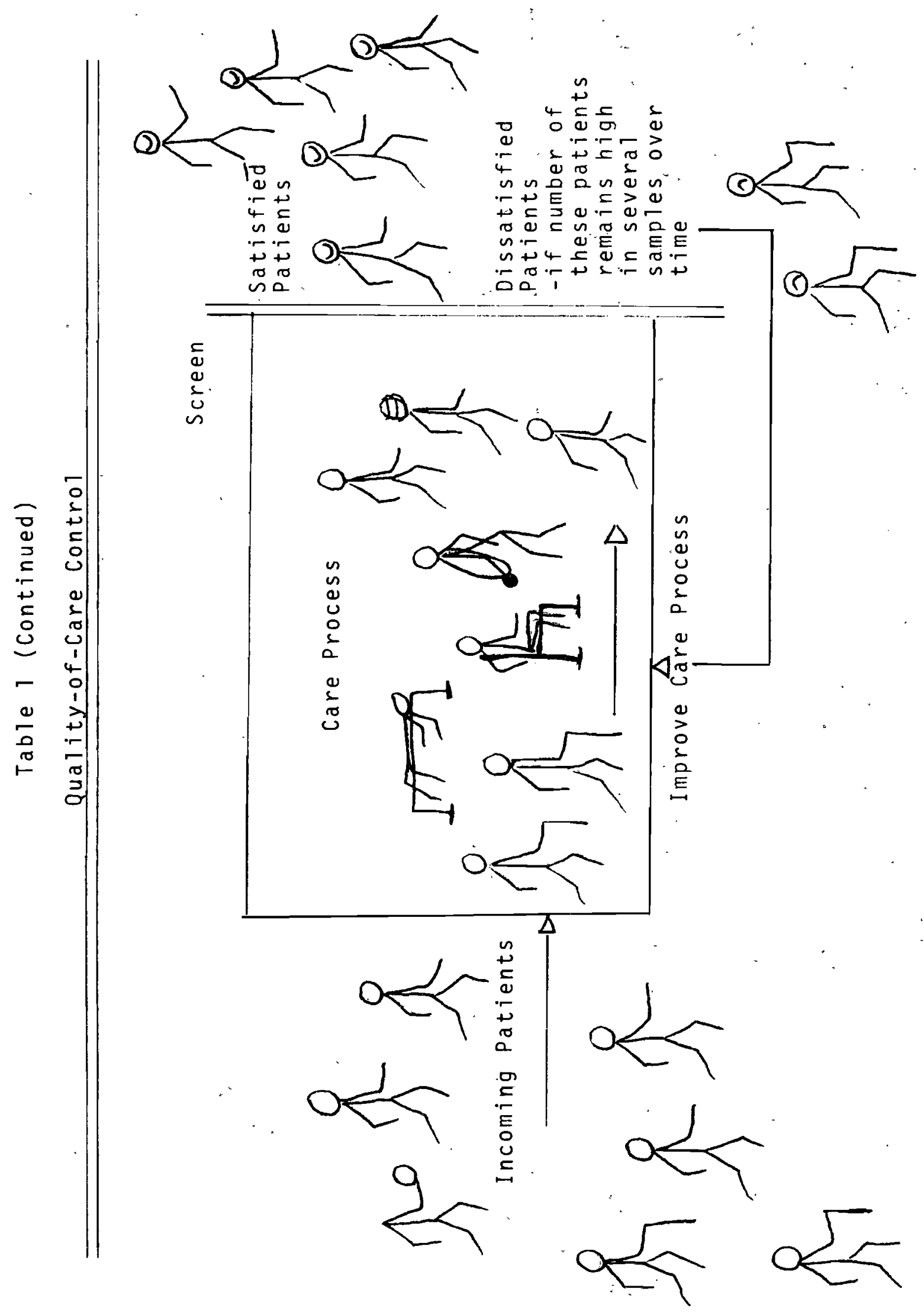


3. Perform a test to determine the number of defective products.

4a. If the number of defectives falls within the ACCEPTANCE RANGE, infer the batch of products is acceptable and send it to market.

4b. If the number of defectives exceeds the ACCEPTANCE RANGE, reject the batch, recycle it, or look into improving the manufacturing process. Improvements made in the process should subsequently result in a decreased number of defective products.

Similarly, a health clinic can be viewed as an operation where incoming patients move through a medical care process and leave with certain perceptions of the care they received. A screen--an on-going patient satisfaction evaluation system-can be erected at the end of the care process to identify sources of satisfaction and dissatisfaction. The steps comprising the evaluation system are:

1. Set a goal--the number of dissatisfied patients tolerated by the clinic director.

2. Select a sample of patients visiting the clinic over a period of time and determine the ACCEPTANCE RANGE in order to account for sampling variation. The ACCEPTANCE RANGE becomes, in effect, the revised goal.

3. Administer a patient satisfaction questionnaire to determine the number of dissatisfied patients.

4a. If the number of dissatisfied patients falls within the ACCEPTABLE RANGE, then infer the care process is perceived satisfactorily.

4b. If the number of dissatisfied patients surpasses the ACCEPTANCE RANGE, a lert the administration and/or residents. If subsequent samples reveal high 
numbers of dissatisfied patients, look into improving the care process. Improving the care process should result in a subsequent reduction in the number of dissatisfied patients.

It cannot, of course, be assumed that a single change in resident behavior or in the system is the direct cause of a change in patients' perceptions. But if administrative or behavioral changes are made and over a period of time the resulting changed satisfaction levels remain the same, there is reason to believe they are associated with each other. Thus an on-going patient satisfaction evaluation system conceptualized as a quality-of-care control mechanism makes possible the continuous monitoring of one aspect of the care process, patient satisfaction.

\section{Questionnaire Development}

The instrument was developed around specific content areas derived from basically two sources; (1) a questionnaire initially developed and tested by ware and snyder (1975) and subsequently revised by Hines et al. (1977), and (2) suggestions from the faculty, residents, and staff at the Department of Family Practice. Ware and Snyder's instrument was used because their test population was similar to the Family Practice Center's and department personnel were heavily involved in the project's developmental phases because this was deemed essential to a successful implementation.

The questionnaire was designed to measure four content areas; (1) the physician-patient relationship, (2) the nursepatient relationship, (3) the receptionist-patient relationship, and (4) waiting time. A total of 12 individual items 
comprised the four content areas and a space was reserved at the end of the questionnaire for comments. Patient demo-. graphic data was gained from billing sheets at another time. A modified Likert response. continuum with five response alternatives ranging from 'strongly agree' to 'strongly' disagree' was used. Individual items were scored separately and a high score indicated a favorable response on each attitude statement. A copy of the questionnaire can be found in Appendix B.

\section{The pilot study}

Population.

The Family Practice Center!s patient population comes from a wide spectrum of socio-economic groups. Approximately 36 percent are pay or partial pay, and the remainder are. either on welfare or disability, Medicare or similar programs. The proportion of male to female patients is two to three. Approximately 60 percent of the patients enrolled are families (more than one person) and 40 percent are singles. The age distribution is: $0-6,19$ percent; $7-17,13$ percent; 18-39, 48 percent; $40-64,14$ percent; $65+; 6$ percent.

Data collection

The following method of data collection was utilized in the pilot study because it was desired to; (1) study the structure of the questionnaire, and (2) distribute meaningful results as soon as possible so as to increase the rapport between. evaluator and staff in the developmental stages. However, a sampling scheme more suitable to the long-term monjtoring of patient satisfaction is recommended in the last 
section of this paper.

All patients visiting the Family Practice Center between January 14 and February 18, 1977 were asked to fill out a questionnaire immediately after their appointment; thus the sampling unit was patient visits, not patients. Even though all patients were questioned during the study time-period, this group was viewed as a sample of patient visits from a population extending over a longer time span. The last person seeing the patient (either a resident or a nurse) encouraged him or her to respond by saying that the family Practice Center wanted to find out how patients felt about their care in order to make improvements if necessary. It was also stressed that their responses would not be seen by their doctor. The patient then answered the questionnaire in the examination room and dropped it in a sealed box as he or she left the clinic. Bias introduced by having those being evaluated distribute the questionnaire was thought to be minimal because all patient visits were being sampled over quite a length of time. Under these conditions, a doctor or nurse would probably not modify his or her behavior to please the patient. An alternative distribution procedure is suggested in the Conclusion and Recommendations section.

A 68 percent response rate was achieved--798 out of 1173 patient visits. A total of 623 patients are represented in 798 patient visits. This appears to represent the clinic's typical overall patient/patient visit ratio. Partial demographic characteristics of the respondents appear in table 2 . The respondents tend to proportionately reflect the total 
sample in both the age and sex categories. The high nonTable 2 .

Partial Demographic Characteristics of the Respondents

\begin{tabular}{lcc}
\hline \hline Sex & Total Sample & Respondents \\
\hline male & $344(29 \%)$ & $211(26 \%)$ \\
female & $\underline{829}(71 \%)$ & $\underline{587}(74 \%)$ \\
Total & 1173 & 798 \\
& & \\
Age & & \\
$0-6$ & $227(19 \%)$ & $161(20 \%)$ \\
$7-17$ & $102(9 \%)$ & $65(8 \%)$ \\
$18-39$ & $563(47 \%)$ & $398(50 \%)$ \\
$40-64$ & $191(16 \%)$ & $67(13 \%)$ \\
$65+$ & $90(8 \%)$ & 798 \\
Total & $1173(8 \%)$ & \\
& & \\
\hline
\end{tabular}

(Percentages rounded to nearest whole percent)

response rate was partially explained by the fact that some patients did not receive a questionnaire because the nurse or resident either forgot or was too busy to give it to the patient. In order to further understand the non-response rate, replies from 40 consecutive non-respondents were-intensively sought. A copy of the questionnaire and a stamped, self-addressed envelope were mailed to them with a letter requesting that they respond and return the form to the Department of Family Practice. Those not replying were telephoned. and asked again to mail back the questionnaire. Approximately 70 percent of this small sample finally answered. Overall," this group of patients appeared to be less satisfied on the 
doctor-related statements than those responding the first time. Because of the differences in which the information was obtained and in the sample sizes, this result was interpreted with caution and not included in the original findings. It does hold, however, an implication for the future monitoring of patient satisfaction; that is, it will be necessary to immediately follow-up those patients not responding the first time in order to obtain an accurate representation of patients' perceptions.

\section{Reporting of Results}

The clinic director set a measurable goal for each of the attitude statements. A distribution of patient satisfaction scores from a previous study conducted at the family Practice Center formed the reference standard for this goal. It was stated in terms of the maximum acceptable number of dissatisfied responses per 100 patient visits. On a positively phrased statement (This visit the receptionists were polite and friendly) this refers to those responding in the 'disagree' and 'strongly disagree' categories. On the negatively phrased statements (Today my doctor made me feel foolish) this refers to the 'agree' and 'strongly agree' responses. The goal was then translated into an 'Acceptable Range'(at a .05 level of significance) for each attitude statement in order to account for sampling variation (Mendenhal1, 1975). It became, in effect, the revised goal. The number of respondents to each statement comprised the sample size used in computing the 'Acceptable Range'. Reports of 
how the Family Practice Center as a whole measured up to the predetermined goal were distributed to the Family Practice faculty, staff; and residents. In addition, "each resident received a report concerning the responses of only those patients he or she treated during the study period. The patients also received a version of the entire clinic report (see Appendix A). 


\section{FINDINGS}

The information generated from this pilot study was treated both as discrete and continuous data. Because the clinic director set measurable goals in discrete terms, part of the findings in this section are reported as frequencies and percentages in relation to the stated goal. The other part of the results are reported in factor analytic terms. Means and standard deviations per attitude statement were computed for the entire clinic and for individual residents but were not used in this evaluation endeavor.

\section{Goal Attainment}

Table 3 depicts the frequency and relative frequency of respondents in each response category for all of the attitude statements in the questionnaire. It also presents an overall view of how the entire Family Practice Center measured up to the predetermined goals. As noted previously, the number of respondents to each statement comprised the sample size used in computing the 'Acceptable Range'. The actual number of dissatisfied responses to each statement is denoted 'Actual'.

Family Practice patients appear to be generally satisfied. with the care they received during the study period, as indicated by the high percentage ( 94.3 percent) of favarable (strongly agree, agree) responses to attitude statement number 12 (In general, I am satisfied with today's visit to the 

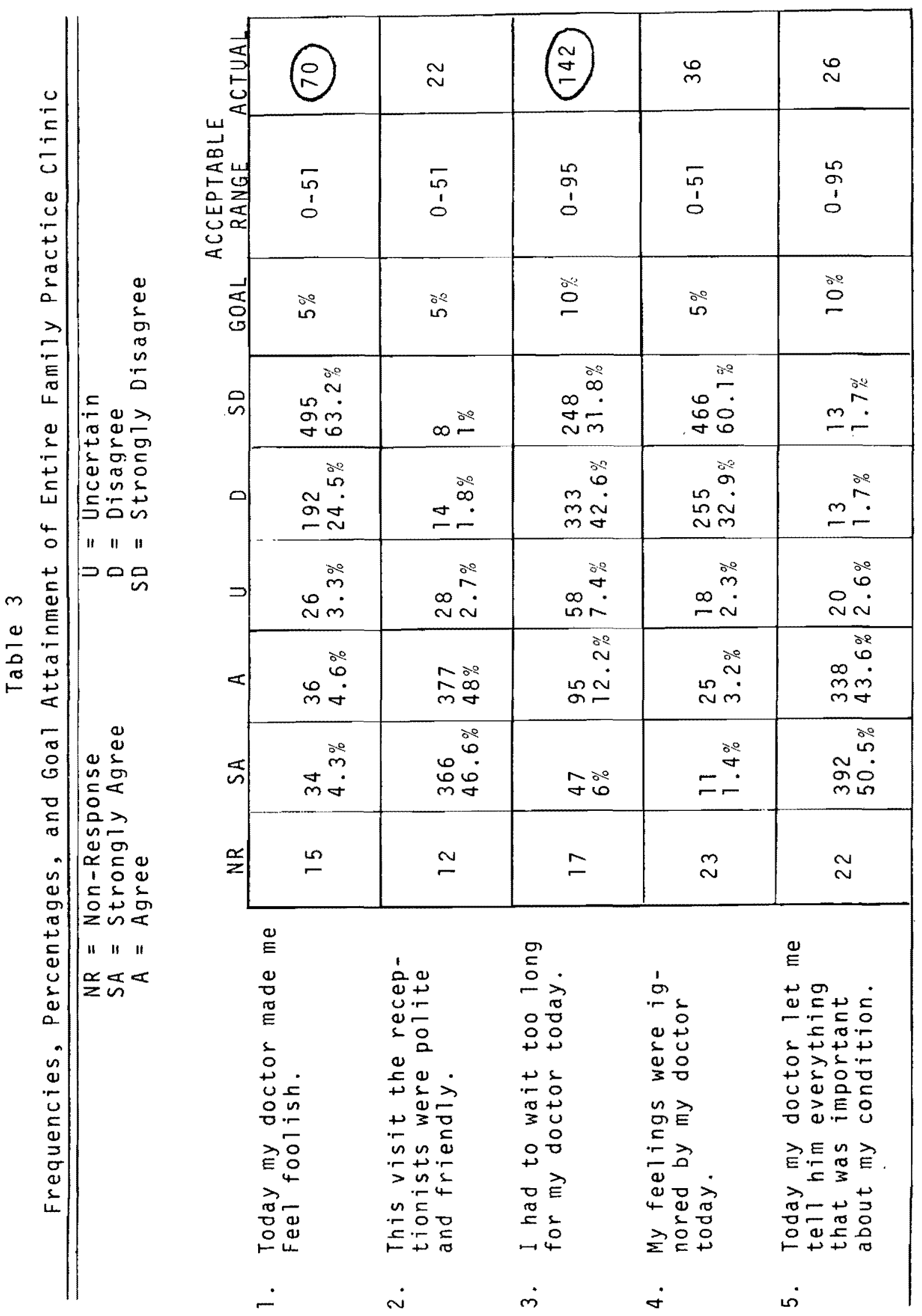


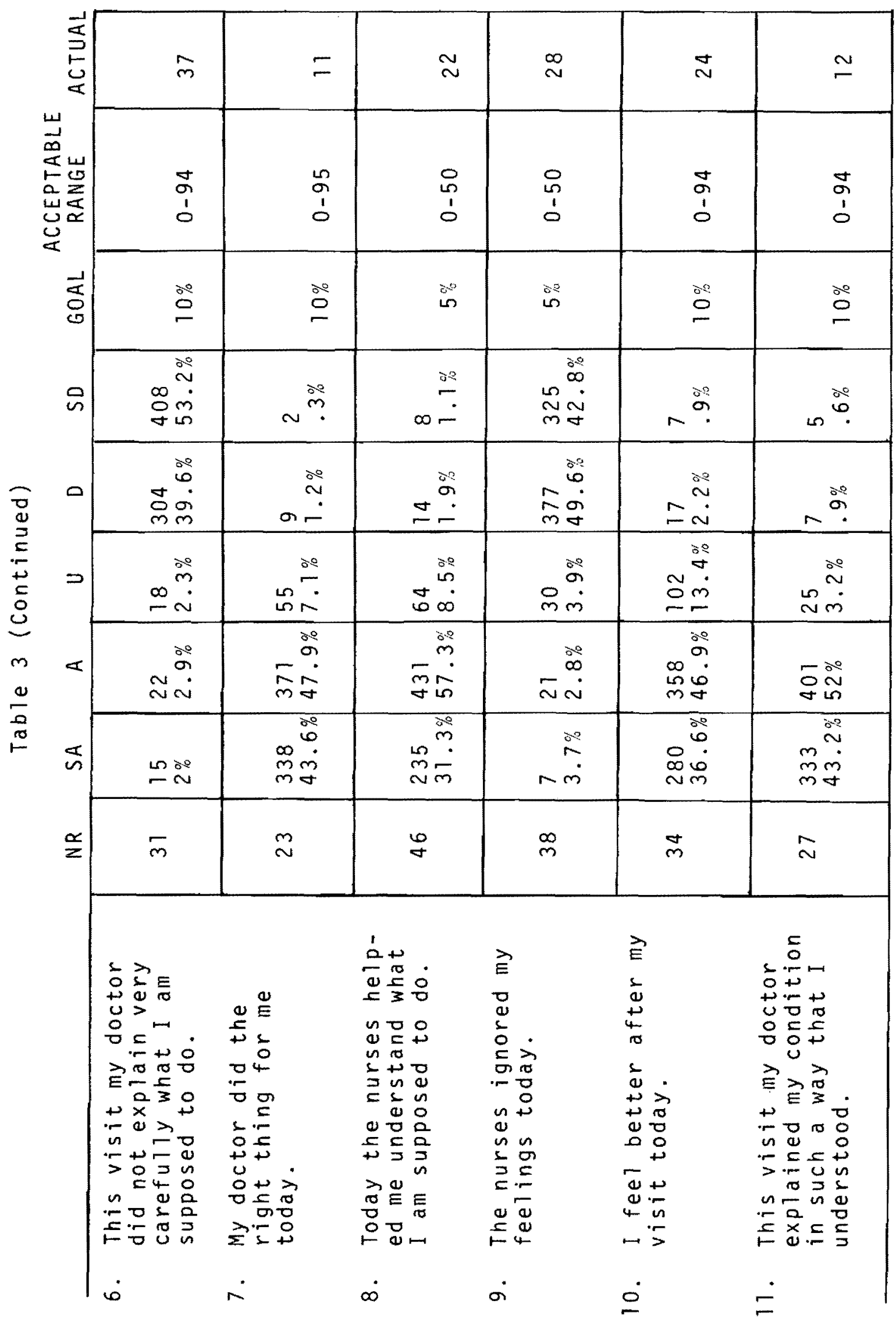




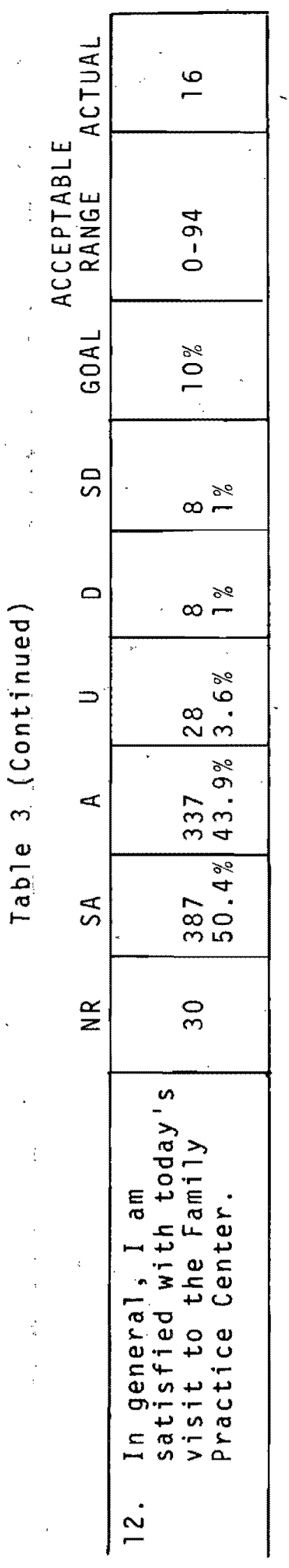


Family Practice Center) and the large number of positive responses. A summary of the patients' comments appears in the clinic report in Appendix A. Only two percent of the respondents registered any degree of dissatisfaction on this statement.

The clinic as a whole fell within acceptable bounds on ten of the attitude statements. On only two (number 1 and number 3 ) did it surpass the 'Acceptable Range' set by the clinic director. A significant portion of the respondents: (1) believe the doctors make them feel foolish; and (2) feel they have to wait too long.

It is rather perplexing that patients perceive the clinic doctors to make them feel foolish, especially since satisfaction registered high on all of the other doctor-related attitude statements, and only a few of the patients' comments support the findings. For instance, one patient asserted, "I came from another city to see a doctor about something important and he made me feel like I was wasting my time." Yet three individual residents, too, exceeded the acceptable bound on this attitude statement. Last year a patient satisfaction survey executed by the Family Practice Department disclosed one resident in this position; however, the goal that time was set somewhat lower. The obvious questions now are; What are Family Practice doctors doing to make the patients feel foolish?, or Does the patient feel foolish regardless of the doctor's behavior? Certainly follow-up studies need to be conducted before any actions are taken. A recommendation regarding possible steps in this direction is made in the last 
section of this paper.

Dissatisfaction with a perceived long waiting time is not new information as last year's study overwhelmingly revealed the same result. An investigation into the causes of this problem is presently underway. Hopefully, administrative actions can then be taken to reduce it. Subsequent monitoring of patient satisfaction should consequently reveal a decrease in dissatisfied responses toward waiting time.

An analysis of individual resident patient visits revealed all of the 24 residents to be within acceptable 1 imits on most of the doctor-related attitude statements. As mentioned above, three exceeded the 'Acceptable Range' on one statement, number 1 (Today my doctor made me feel foolish).

\section{Factor Analysis}

Factor analysis (Harman, 1976) was applied to the data primarily to aid in the further refinement of the questionnaire. This statistical technique was used to investigate whether or not the structure built into the questionnaire was actually present and whether or not the attitude statements were related.

As mentioned in the Methods section of this paper, the questionnaire was developed around specific content areas, and these content areas were derived from two sources; questionnaires from other studies dealing with similar populations, and (2) the faculty, residents, and staff at the Family Practice Department. Thus factor analysis would empirically reveal whether the patients' conceptualization 
of the content areas matched the a priori derived structure. It would also disclose which attitude statements were measuring the same dimensions of patient satisfaction.

The factors were extracted by the principle components method and varimax orthogonal rotation was initially performed. Because four factors were expected, that number was specified. The first computer output revealed a need to extract five factors so the program was rerun and interpretations were made. All loadings greater than. 5 were considered to belong to a particular factor. Most of the attitude statements loaded high on only one factor. One loaded fairly high on two. This indicated a need to reconsider that attitude statement--either to remove it or rewrite it. A recommendation is made at the end of this paper to rewrite it. A large portion of the variance of each statement was explained by the five factors; the communalities of all of the variables were greater than .57 . Table 4 portrays the attitude statements in abbreviated form, communalities, factors, and factor loadings greater than .3 .

The first two factors encompass the 'doctor-patient relationship'. The most important factor has to do with a reciprocal communication between the patient and the doctor regarding the patients' condition. This appears to result in the patient feeling better because he or she now knows what the problem is. The other 'doctor-patient relationship' dimension relates patients' feelings to how carefully the doctor explained treatment instructions. 'Waiting time', 'nurses', and 'receptionists' each comprised separate factors. 
Table 4 .

Factor structure of the Questionnaire

\begin{tabular}{|c|c|c|c|c|c|c|}
\hline Attitude Statements & I & I I & I I. I & I $V$ & v & $\begin{array}{l}\text { Commu- } \\
\text { nalities }\end{array}$ \\
\hline $\begin{array}{l}\text { Doctor let me tell } \\
\text { all }\end{array}$ & .527 & -.329 & & & .356 & $\begin{array}{c}.603 \\
\ddots\end{array}$ \\
\hline $\begin{array}{l}\text { Doctor did right } \\
\text { thing }\end{array}$ & .787 & & & & & .699 \\
\hline $\begin{array}{l}\text { Doctor explained so } \\
\text { I understood }\end{array}$ & .813 & & & & & .701 \\
\hline I feel better & .761 & & & & & $.633^{\prime}$ \\
\hline $\begin{array}{l}\text { General satisfac- } \\
\text { tion }\end{array}$ & .622 & & & . & & .572 \\
\hline $\begin{array}{l}\text { Doctor made me feel } \\
\text { foolish }\end{array}$ & & -.839 & & & & .724 \\
\hline $\begin{array}{l}\text { Doctor ignored feel- } \\
\text { ings }\end{array}$ & & -.698 & & -.323 & & .663 \\
\hline $\begin{array}{l}\text { Doctor didn't explain } \\
\text { carefully }\end{array}$ & & -.547 & & -.429 & . & .575 \\
\hline $\begin{array}{l}\text { I had to wait too } \\
\text { long }\end{array}$ & & . & .937 & . & . & .929 \\
\hline $\begin{array}{l}\text { Nurse explained so } \\
\text { I understood }\end{array}$ & .403 & & & -.708 & & .721 \\
\hline $\begin{array}{l}\text { Nurse ignored feel- } \\
\text { ings }\end{array}$ & & & & -.854 & & .798 \\
\hline $\begin{array}{l}\text { Receptionists polite } \\
\text { and friendly }\end{array}$ & " & . & & & .947 & .934 \\
\hline
\end{tabular}


A final computer run with a specified oblique rotation disclosed virtually no relationship among factors. They appear to stand fairly independently of each other.

It is apparent from the factor analysis that Family Practice patients discriminate between the different aspects. of the clinic encounter. In fact, they appear to perceive the providers as members of a health care team each having a separate but essential function. The patients also tend to differentiate between somewhat inconvenient and truly depersonalized care as waiting time was not at all associated. with any of the other attitude statements. Perceived general satisfaction, again, tends to be associated with a reciprocal communication between patient and doctor; each giving. the other information and the patient leaving the encounter with an improved knowledge of what the problem is and feeling better as a result.

In general these factors are as expected, compatible with the content areas built into the questionnaire. 


\section{CONCLUSION AND RECOMMENDATIONS}

The question posed in the Introduction to this paper was, How feasible is the continuous operation of the patient satisfaction evaluation system? The reply is that it appears to be very feasible. The pilot study proceeded with minimal. resistance and the results were greeted with enthusiasm by the faculty, residents, and staff. This success can most likely be attributed to several factors. First; resistances and barriers were minimized and the attendant staff morale maximized by involving almost everyone in the planning of the project. Strong administrative support was also present throughout the study, primarily because the Department of Fami.ly Practice is committed to improving the quality of medical care and education. The results were reported quickly and in a manner easily comprehended by the reader. Finally, the concept of quality control and continuous feedback is in itself a desired and essential ingredient to any institution or person demanding excellence, and this appears to be a goal of the Department as well as individual residents.

It is unequivocally recommended that the patient satisfaction evaluation system be integrated into Family Practice with the following inor revisions and additional considerations.

\section{Questionnaire}

1. Retain the format and length of the original questionnaire, 
but reorder the attitude statements to reflect the patients' flow through the clinic encounter. For example, the first statement should be, "This visit the receptionists were polite and friendly." Next, "I had to wait too long for my doctor today;" and so on.

2. Add 'in order to make improvements if necessary' to the first line of the introduction.

3. Include the sentence, "If you have no feelings one way or the other, circle 'neutral'," at the end of the introduction.

4. Change 'uncertain' in the response continuum to 'neutral'. The word 'uncertain' appears to act as a waste basket. It is too easy for patients to circle 'uncertain' without giving much thought to the other response choices. On the other hand, 'neutral' forces a respondent to consider the other options first and if none fit, then as a last resort, respond 'neutral'.

5. Change attitude statement number 6 to read, "This visit my doctor didn't explain his instructions so that I understood." The way the present statement reads, the doctor could conceivably explain carefully and the patient not understand a word of what was said. In fact, one of the findings in this pilot study suggests that this is indeed the case--a moderate association was disclosed between statement number 6 (This visit my doctor didn't explain very carefully what I am supposed to do) and statement number 8 (Today the nurse helped me understand what I am supposed to do). The above revision should better measure 
the doctor's ability to communicate instructions.

6. Change attitude statement number 10 (I feel better) to "I feel somewhat better." The purpose of initially including this statement in the questionnaire was to attempt to measure the objective that each patient should somehow feel better after a visit to the doctor--not necessairly physically better but perhaps mentally more at ease. The addition of 'somewhat' seems to better achieve that purpose by allowing the patient to respond to a relative 'betterness'.

7. Add 'if applicable' after statement 8 (Today the nurses helped me understand what I am supposed to do) and statement 9 (The nurses ignored my feelings today).

\section{Sampling Scheme}

1. Retain the general acceptance sampling framework but randomly sample clinics (half days) per resident year. Then question all those patients attending each clinic sampled. This is a typical probability sampling scheme utilizing; (a) strata (resident years) to increase the homogeneity of the respondents and to insure proportionately equal representation of patient visits per resident year, and (b) clusters of patient visits (clinics) as the primary sampling unit and individual patient visits as the secondary sampling unit. The number of clinics sampled will depend upon the number of reports desired per year. It is recommended that results be reported twice a year for three interrelated reasons: (a) Approximately 36 patient visits, randomly selected, per resident are needed to 
achieve a valid inference. This figure was derived from the following standard formula (Mendenhal.1, 1975) for computing sample sizes:

$$
\begin{aligned}
& 2 \frac{(.9)(.1)}{n}=.1 \\
& p=.9-\text { the average satisfaction leve } 1 \\
& \text { achieved in the pilot study } \\
& q=.1 \\
& \text { error of estimation }=.1
\end{aligned}
$$

It is easy to obtain the required number of patients for third year residents in a relatively short period of time, but not so easy for first and second year residents, as. they treat far fewer patients. (b) It is also important to make data collection minimally disruptive to the normal operation of the clinic. This can be achieved by sampling a minimum of clinics. (c) Finally, more than two reporting periods per year would require proportionately more staff time for overseeing the dissemination of. the questionnaire, tabulating data, and writing reports.

More specifically, half-year reporting intervals should be utilized. These would include approximately four six-week periods each. Assuming each resident on the average treats 6 patients per clinic and allowing for some slack, it would be necessary to sample eight clinics per half year per resident year to meet the required resident sample size. In order to achieve a spread among the four six-week periods, choose two clinics at random per six-week period per resident year and then ques- 
tion all patients visiting each clinic sampled.

2. The questionnaire dissemination procedure used in the pilot study (doctors and nurses distributing the questionnaire) should be abandoned. Bias was less of a problem then because the study included all patient visits for quite a length of time. Under these conditions, a doctor or nurse would probably not modify his or her behavior to please the patient. However, in order to minimize bias in the previously recommended revised sampling scheme, it will be necessary to enlist an independent person (independent of those being evaluated) to distribute the questionnaire. If six total clinics (two clinics $x$ three resident years) are sampled every six weeks, this would require approximately three days each period of this person's time. He or she could also be responsible for tabulating the data and writing reports. Those not responding need to be intensively followed-up in order to obtain an accurate representation of patients' perceptions--this person could also take care of this.

3. Continue to use 'Acceptable Ranges' in reporting results to the residents, faculty, and staff. Retain the less technical 'letter' style of reporting results to patients.

\section{Additional Considerations}

1. Introduce the patient satisfaction evaluation system to the incoming first year residents as a group. It should be described in terms of its nonpunitive evaluative purpose and potential. A brief summary of the pilot study results could be included. 
2. Introduce the system in other clinics at the Health Sciences center and in private practices. This would afford a comparison of factor structure and satisfaction levels across populations and settings.

3. Complete the 'waiting time' study by identifying contributory causes and suggesting ways to reduce it. It is suggested to look at reducing both the mean waiting time and the variation.

4. Investigate further the 'foolish' problem by; (a) interviewing foolish-feeling patients to find out exactly what it is that makes them feel foolish, (b) gathering demographic and health status information to find out who these people are and what health problems they have, and (c) videotaping and subsequently objectively analyzing the actual doctor-patient interaction (with their permission, of course).

5. Have someone routinely check the 'Suggestion Box' and communicate to the administration the patients' perceptions of clinic problem areas.

6. Utilize the data collected by the on-going patient satisfaction evaluation system to answer other pertinent research questions, such as: How does compliance or health status relate to general satisfaction? Are new patients more or less satisfied than 'established patients? Does the ability to pay seem to affect a patient's level of satisfaction with care? Do patients of first year residents conceptualize the doctor-patient relationship differently from patients of second or third year residents? 
7. The Human Studies Committee at the Health Sciences Center requires researchers to obtain release signatures from patients allowing the researchers to use the patients.'. responses, records, etc. in their studies. The Family Practice Center receptionists could begin immediately requesting those essential signatures from patients as. they arrive for appointments.:

8. One caveat needs to be emphasized; that is, the possibility exists that the levels of satisfaction achieved in the pilot study may decrease in the future. This is possible because the continuous monitoring of patient satisfaction may provide an environment conducive to honest patient criticism. It is true that all 'one shot' patient satis:faction studies thus far have yielded unusually consis tent high levels of satisfaction. This could be due in part to a strong learned response on behalf of the patient to respond in a socially acceptable manner when asked about such a revered institution as medicine. Continuous monitoring and routine feedback to the patients carried out in a nonpunitive atmosphere could break this hypothesized socially acceptable response, and ultimately result in lower satisfaction levels for a time.

9. The continued success of this system is contingent upon a prompt response, if possible, by the Family Practice Department personnel to those problems perceived by patients. 


\section{SELECTED BIBLIOGRAPHY}

Babbie, Earl. Survey Research Methods. Belmont, California: Wadsworth Publishing Company, Inc., 1973.

Ben-Sia, Zeev. "The Function of the Professional's Affective Behavior in Client Satisfaction: A Revised Approach to Social Interaction Theory." Journal of Health and Social Behavior. Vol. 7 (March, 1976): 3-11.

Berkanovic, Emil, and Marcus, Alfred C. "Satisfaction with Health Services: Some Policy Implications." Medical Care. Vol. XIV, No. 10, (October, 1976): $873-879$.

Harman, Harry. Modern Factor Analysis, 4th ed. Chicago and London: The University of Chicago Press, 1976.

Hines, Brian L.; Clarkson, Quentin D.; and Smith, David D. "Development and Use of a Patient Satisfaction Questionnaire." The Journal of Family Practice. Vol.4, No. 1, 1977: $148-149$.

Hulka, Barbara S.; Zyzanski; Stephen J.; Cassel, John C.; and Thompson, Shirley J. "Scale for the Measurement of Attitudes toward Physicians and Primary Medical Care." Medical Care. Vol. VIII, No. 5, (SeptemberOctober, 1970): 429-435.

Hulka, Barbara S.; Zyzanski, Stephen J.; Cassel, John C.; and Thompson, Shirley J. "Satisfaction with Medical

Care in a Low Income Population. "Journal of Chronic Diseases. Vol. 24, 1971: 661-673.

Hulka, Barbara S.; Kupper, Lawrence L.; Cassel, John C.; and Thompson, Shirley J. "A Method for Measuring Physicians' Awareness of Patients' Concerns." HSMHA Health Reports, (August, 1971): 741-751.

Hulka, Barbara S.; Kupper, Lawrence L.; Daly, Mary B.; Cassel, John C.; and Schoen, Frederic. "Correlates of Satisfaction and Dissatisfaction with Medical Care: A Community Perspective." Medical Care. Vol. XIII, No. 8 , (August, 1975): 648-658.

Hulka, Barbara S.; Kupper, Lawrence L.; Casse1, John C.; and Babiniau, Robert A. "Practice Characteristics and Quality of Medical Care: The Doctor-Patient Relationship." Medical Care. Vol. XIII, No. 10, (October, 1975): 808-820. 
Kisch, Arnold J., and Reeder, Leo G. "Client Evaluation of Physician Performance." Journal of Health and Social Behavior. No. 10, 1971: 51-58.

Lebow, Jay. "Consumer Assessments of the Quality of Medical Care." Medical Care. Vol. XI1, No. 4, (April, 1974): $328-337$.

Lebow, Jay. "Evaluation of an 0utpatient Pediatric Practice Through the Use of Consumer Questionnaires." Medical Care. Vo1. XIII, No. 3, (March, 1975): 250-255.

Linn, Lawrence S. "Factors Associated with Health Care." Health and Society. (Fall, 1975): 531-548.

McGuire, C. H. "Educational Program Research and Development." Journal of Medical Education. Vol. 48, 1973: 137-143.

Mendenhall, William. Introduction to Probability and Statistics, 4 th ed. North Scltuate, Massachusetts: Duxbury Press, 1975.

Oppenheim, A. N. Questionnaire Design and Attitude Measurement. New York: Basic Books, Inc., 1966.

Ware, John E., and Snyder, Mary K. "Dimensions of Patient Attitudes Regarding Doctors and Medical Care Services." Medical Care. Vol. XIII, No. 8, (August, 1975): 669-682.

Ware, John E., Jr.; Wright, W. Russel; Snyder, Mary K; and Godwin, Chu C. "Consumer Perceptions of Health Care Services: Implication's for Academic Medicine." Journal of Medical Education. Vol. 50, (September, 1975): $839-$ 848 .

Weiss, Carol H. Evaluation Research. Englwood Cliffs, New Jersey: Prentice-Hall, Inc., T972.

Zyzanski, Stephen J.; Hulka, Barbara S.; and Cassel, John C. "Scale for the Measurement of 'Satisfaction' with Medical Care: Modifications in Content, Format, and Scoring." Medical Care. Vol. XII, No. 7, (July, 1974): 611-620. 

Tate:

ro:

From:

iubject:

May 27,1977

(Name Deleted)

Lynda Ater

PATIENT SATISFACTION MONITORING PROJECT REPORTS

These reports summarize the initial results of the patient satisfaction evaluation study you all participated in between January 14 and February 18 of this year. This survey was a pilot study designed to precurse and aid in the development of a continuous patient satisfaction evaluation system at the Family Practice Center. Ultimately, this means that on-going samples of patient visits will be generated and analyzed at different intervals throughout the year and routinely reported to individual residents and to the Family Practice Center as a whole. Thus, patient satisfaction will be monitored and the evaluation results of this outcome utilized in the Family Practice Center's decision-making processes.

Because any evaluation endeavor requires the setting of quantifiable objectives against which results can be measured, Dr. Smith set a measurable goal for each attitude statement. The goal was stated in terms of the maximum acceptable number of dissatisfied responses per 100 patient visits. On a positively phrased statement (This visit the receptionists were polite and friendly.) this refers to those responding in the 'disagree' and 'strongly disagree' categories. On the negatively phrased statements (Today my doctor made me feel foolish.) this refers to the 'agree' and 'strongly agree' responses. For attitude statements $1,2,4,8$, and 9 , the goal was 5 or less out of $100(5 \%)$. For statements $3,5,6,7,10,11$, and 12 , it was 10 or iess out of $100(10 \%)$.

As you peruse the following reports, note that I have translated Dr. Smith's single number goal into an 'Acceptable Range' for each of the attitude statements. This was done in order to account for sampling variation. For a detailed discussion of the statistical formulation of the 'Acceptable Range' the reader is referred to An Introduction to Probability and Statistics by William Mendenhall. The actual number of dissatisfied responses to each attitude statement is denoted 'Actual'. For example, a 5 out of 100 standard would be adjusted to an 'Acceptable Range' of $0-9$ per 100. Thus, if a single sample of 100 patient visits yields 7 (Actual) dissatisfied responses to a particular statement, it is considered to be within acceptable bounds. It is also important to note that the 'Acceptable Range' varies with different sample sizes and that a larger sample is generally more informative. 
Even though Dr. Smith's goals have been utilized in the following reports, you should use your own judgment, too, in interpreting the meaning of these results. To assist in this interpretation, I have put together a summary of my own personal impressions of the outcome of both the entire sample of patient visits and individual resident samples. Remember, the basis for these reports are the patients' perceptions of your performance; consequently, they may or may not reflect the true situation.

I am also very interested in learning how each of you viewed the pilot study and how you feel about this kind of feedback. Do you think you had enough input into the project design? Do you find this information useful? Are there ways that I could improve the reporting of results to you? Please think about how you would address these questions, and I will contact some of you within the next week about your views. Or, if you desire, leave your comments with Brian Hines (as I am not always available) and I will retrieve them from him.

This report package includes:

1. The overall response rate and partial demographic characteristics of the respondents as a whole.

2. A table depicting the frequencies and percentages per response category for the entire sample and all of the attitude statements.

3. An overall look at how the Family Practice Center measured up to the predetermined goals.

4. An edited version of the Family Practice Center patients' comments.

5. My personal impressions of the results.

In addition, each resident will receive:

1. The response rate and partial demographic characteristics of their own respondents.

2. A table depicting the frequencies and percentages per response category for their sample and the physician related statements only.

3. Respective resident levels of goal attainment on physician related statements only.

4. An edited version of the comments made by their patients.

5. My personal impressions of their sample results. 


\section{ENTIRE FAMILY PRACTICE REPORT}

A shor.t questionnaire was given to all patients visiting the Family Practice Center between January 14 and February 18 of this year. The questionnaire was designed to monitor patient satisfaction after each visit. Even though al1 patients were questioned during the study time-period, this group was viewed as a sample of patient visits from a population extending over a longer time period.

Because the sampling unit was "patient visits", some patients appear in the study more than once. A total of " 623 patients are represented in 798 patient visits. All of the following data, however, are presented in "patient visit" terms. An overal1 response rate of $68 \%$ was achieved; 798 out of 1173 . Patient visits outside of regular clinic hours are not included in this s.tudy.

Partial demographic characteristics of the respondents follow:

$\underline{\text { Sex }}$

Male

Female

TOTAL

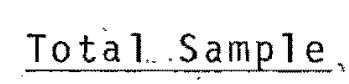

$344(29 \%)$

$829 .(71 \%)$

1173
Respondents

$211(26 \%)$

$587(74 \%)$.

798

$\underline{\text { Age }}$

$0-6$

$7-17$

$18-39$

$40-64$

$65+$

\begin{tabular}{rr}
227 & $(19 \%)$ \\
102 & $(9 \%)$ \\
563 & $(47 \%)$ \\
191 & $(16 \%)$ \\
90 & $(8 \%)$ \\
\hline
\end{tabular}

$\begin{array}{r}161 \\ 65(20 \%) \\ 398(5 \%) \\ 107(13 \%) \\ 67 \times(8 \%) \\ \hline\end{array}$

TOTAL

117.3

798

(Percentages rounded to nearest whole percent) 


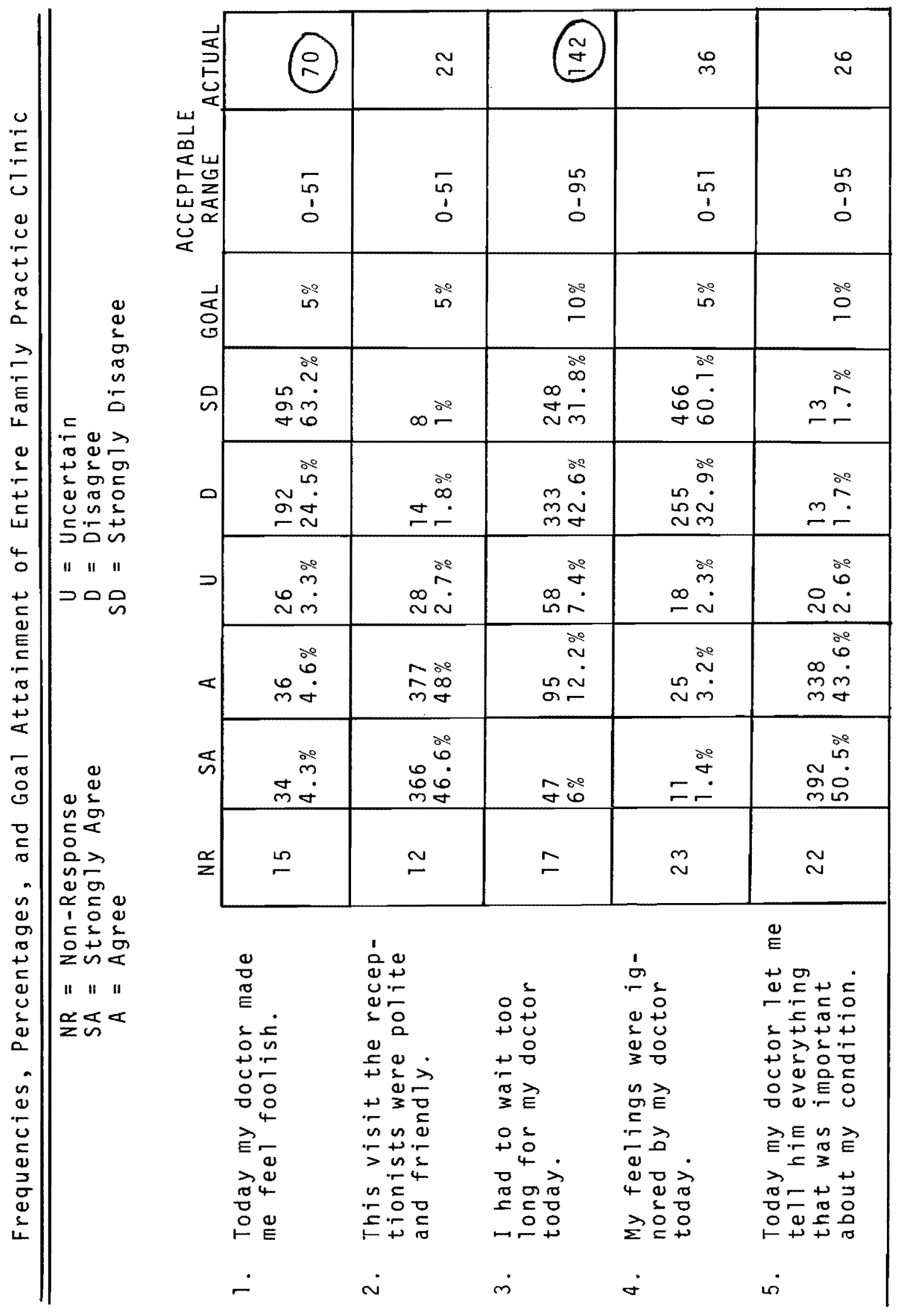




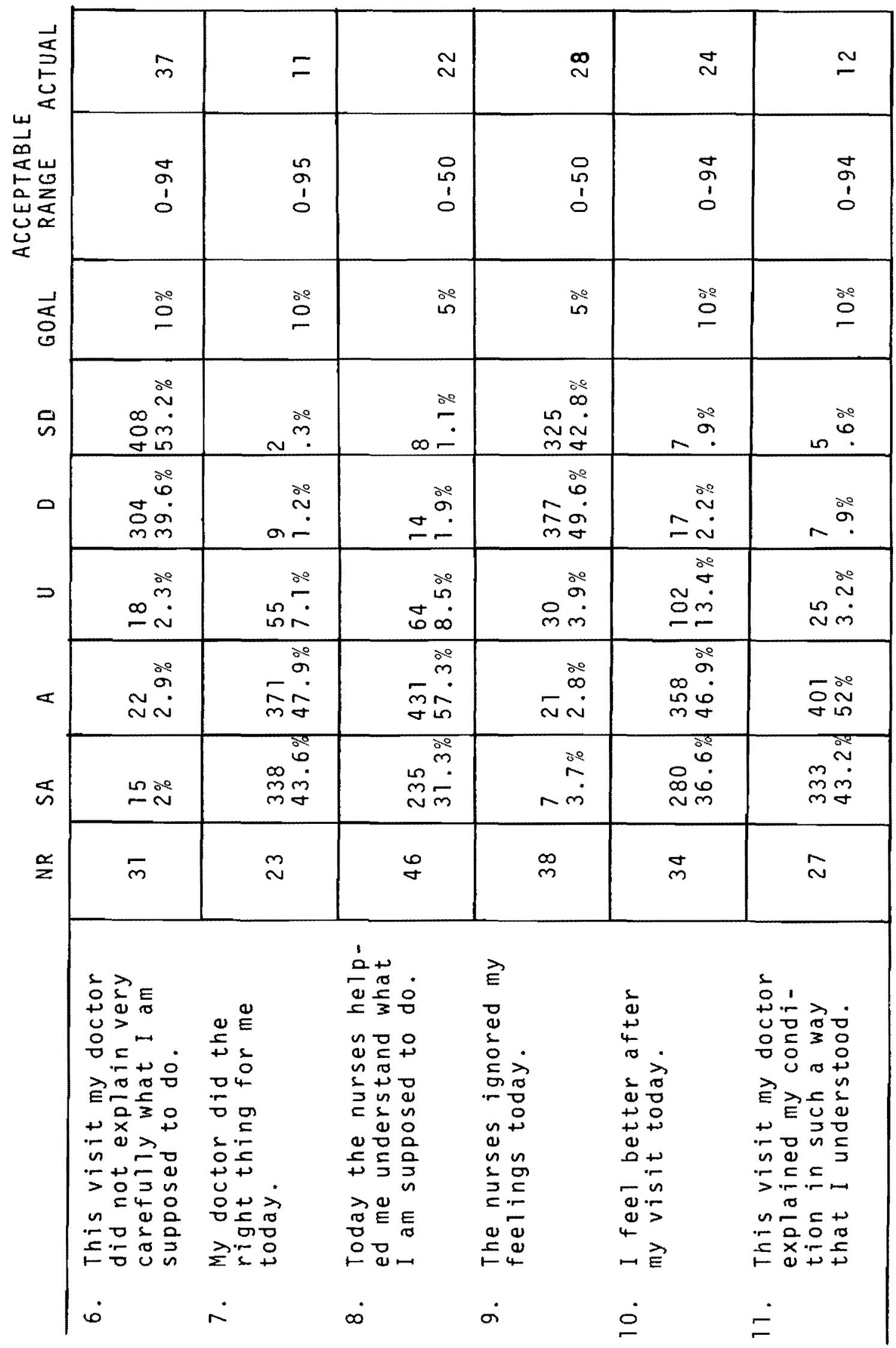




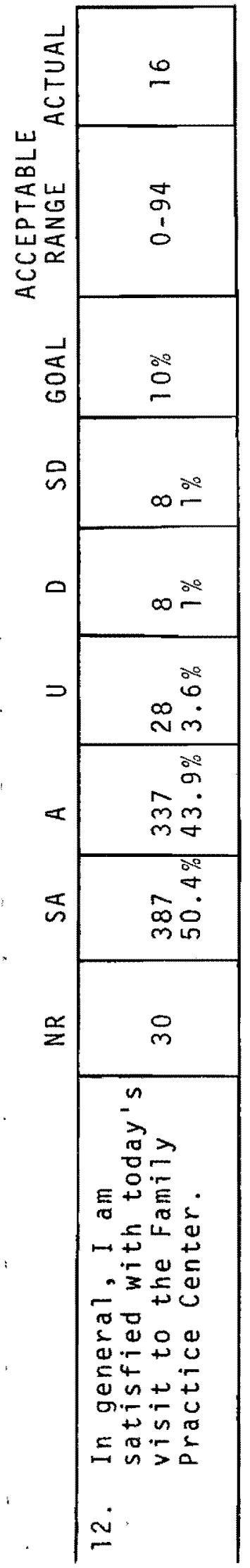




\section{Family Practice Center Patients' Comments}

Category

Number

General positive feeling toward the Family Practice Center.

Total waiting time too long.

Doctors considerate, relate well", and ex-

plain things carefully.

Competent, warm staff.

Courteous and helpful staff.

Everyone really concerned about patients.

objections to questionnaire.

Quick service today.

Too long of a wait in examination room and not enough time with the Doctor.

Desire same doctor all of the time.

Doctors should explain things so patient understands.

Good experience as a work-in.

More evaluations.

Need handicapped parking close by.

Faster service for prescriptions and more medicines available.

Pleased to have health insurance through Project Health.

More billing information available at reception window.

Incompetent staff.

Parking is a problem--too few spaces and, not enough time on the meters.

More current magazines and a greater selection in the waiting area and examination room. 


\section{Category}

Number

Need a separate area for children.

Toys need to be routinely washed.

Nurses should explain things so patient understands

Hard to get appointment.

Uncomfortable waiting area - too hot.

As effective as can be expected for a university clinic. 


\section{My Impressions of the Entire Sample Results}

Family Practice patients appear to be generally satisfied with the care they are receiving at the clinic, as indicated by the high number of favorable responses to statement number 12 and the large number of positive comments. However, the clinic as a whole exceeded the acceptable bounds set by Dr. Smith on two of the statements. A significant portion of Family Practice patients: (1) believe the doctors make them feel "foolish", and (2) feel they have to wait too long.

It is somewhat of a puzzle that patients perceive the clinic doctors to make them feel "foolish", especially since satisfaction registered high on all the other doctor-related questions; and only a few of the patients' comments, in my judgment, support the findings. Yet, a few individual residents, too, surpassed the acceptable bounds on this attitude statement. Last year's patient satisfaction survey results disclosed one resident in this position; however, the goal that time was set somewhat lower, 10 or less out of 100 dissatisfied responses. The obvious questions now are: "What are Family Practice doctors doing to make the patients feel "foolish"? or "Does the patient feel foolish regardless of the doctor's behavior?" Certainly, follow-up studies need to be conducted before any action is taken. In-depth interviews with foolish-feeling patients and video-tapes of the actual

l time patient and doctor spend together would provide further insight.

Dissatisfaction with a perceived long waiting time is not new information as last year's survey overwhelmingly revealed the same result. A few months ago, you may remember, Brian Hines designed and executed a project to find out exactly how long patients had to wait and where the longest wait occurred. His findings suggest the wait is indeed "too long." He plans to further research the problem in an effort to reduce $j t$. Subsequent monitoring of patient satisfaction should consequently reveal an increase in favorable responses toward waiting time. 


\section{INDIVIDUAL RESIDENT REPORT}

Dr.

Sampling Unit: Patient Visits

Response Rate: 59 out of $82-72 \%$

Demographic Characteristics of Respondents:

$\underline{\operatorname{Sex}}$

Ma 1 e

Female

TOTAL

Age

$$
\begin{aligned}
& 0-6 \\
& 7-17 \\
& 18-39 \\
& 40-64 \\
& 65+
\end{aligned}
$$

TOTAL

\section{Respondents}

$$
\begin{array}{r}
20(3.4 \%) \\
39 \quad(66 \%) \\
\hline
\end{array}
$$

59

\section{Your Patients' Comments}

I was a work-in; I was taken care of by a Doctor who was not familiar with me - but he did very: well by me.

\section{My Impression of Your Sample Results}

Overal1, a majority of the patients you treated during the study period appear to be very satisfied with the care they received. You surpassed the acceptable bound set by Dr. Smith on only one attitude statement, \#1 (Today my doctor made me feel foolish). I find the result rather perplexing as your patients responded quite positively to the other doctor related attitude statements. You are also within acceptable bounds on the other statements.

This finding, of course, may not reflect the true situation, or it may reveal something in your behavior that makes patients feel foolish. It is difficult to know the true answer using these results alone; however, there is enough evidence to reveal that this is the perception of several of your patients.

Generally, your patients appear to be quite satisfied with their care.

(Percentages rounded to nearest whole percent) 

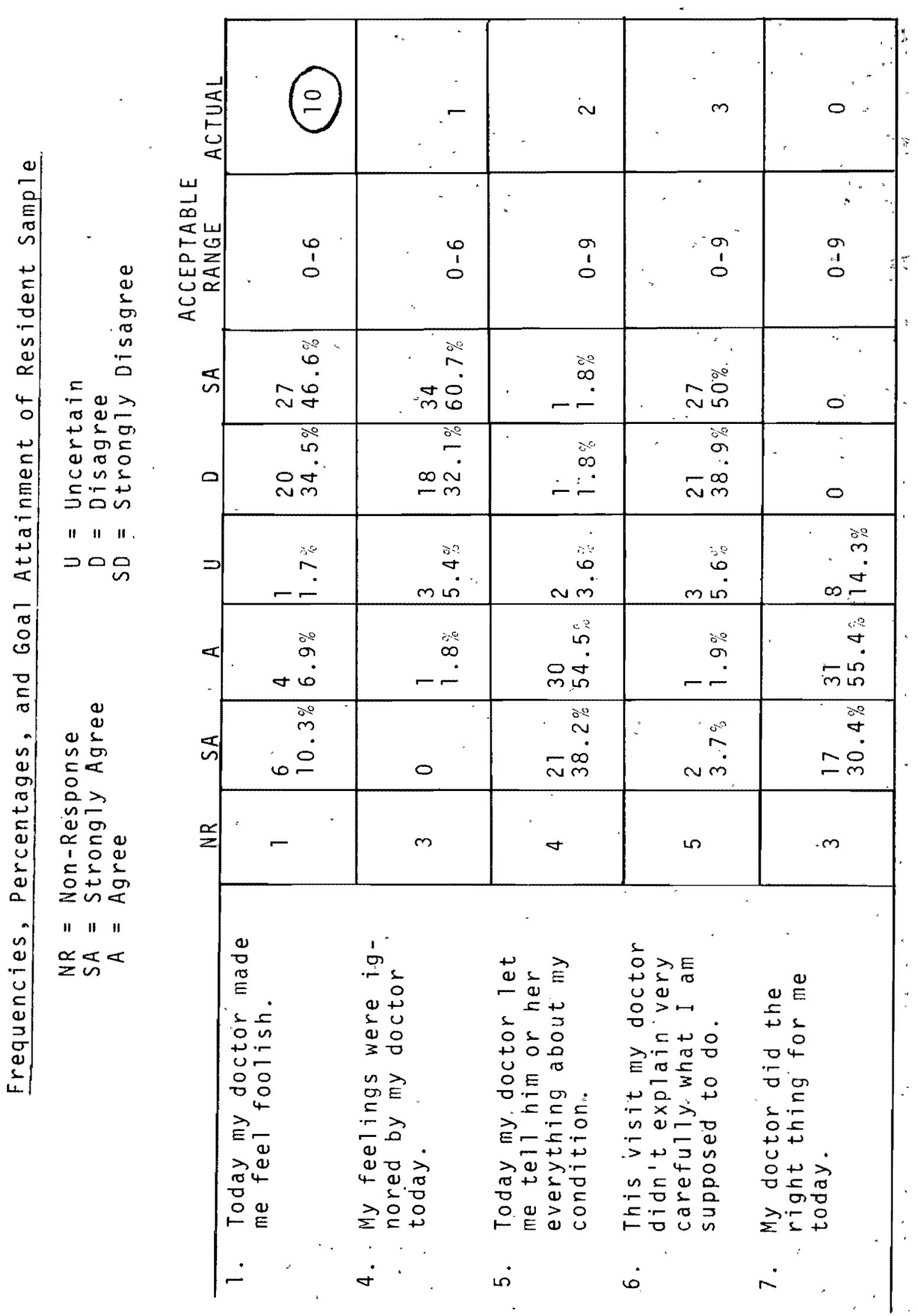


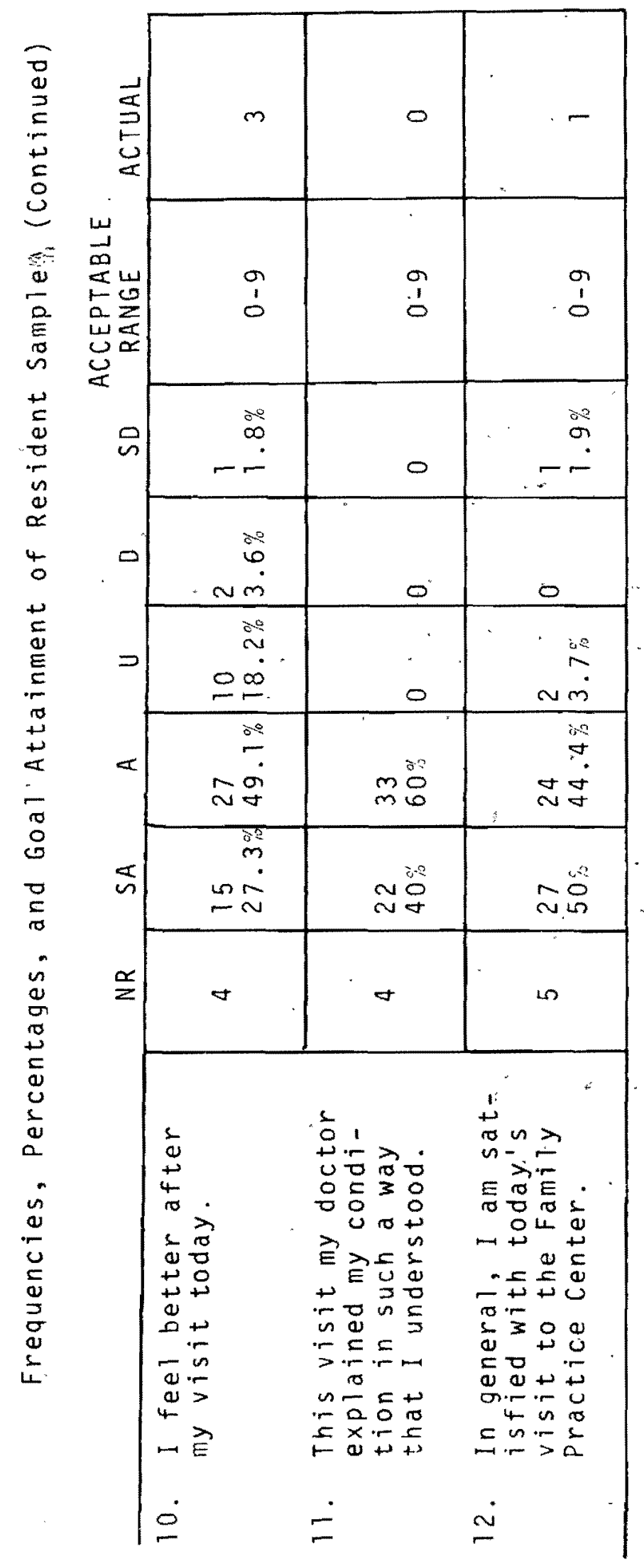




\section{PATIENT SATISFACTION SURVEY REPORT}

Dear Patients:

This report summarizes the results of the patient satisfaction survey some of you participated in a few months ago. You may remember that the survey was conducted because the Family Practice Center wanted to know how their patients felt about the care they were receiving in order to make improvements if the survey results revealed it necessary.

We11, it turned out that most of you were very satisfied with your care. Some of you, however, had complaints about the way a particular doctor made you feel. These doctors have been informed of your feelings (of course the doctor does not know who made the complaints). This kind of feedback to a young physician is very much appreciated as it tells him how his patients view his conduct. It was also very apparent that a significant number of you objected to waiting too long for your doctor. The Family Practice Center has already begun to look into this problem. We realize that patients also have demands on their time and that spending $11 / 2$ hours or more in a clinic is not appreciated. Hopefully the waiting time problem will soon be reduced.

Many of you also made suggestions for improvement in other areas of the Family Practice Center. We carefully considered each and every one and have made changes where we could. For instance:

(1) The clinic now has a larger selection and more recent editions of magazines; (2) The visual material on the wall is different;

(3) There are more magazines in the examination rooms; (4) The toys are being washed regularly; and (5) If you receive a parking ticket while you are visiting the Family Practice Center, you can get it stamped by the receptionist and avoid the charge (provided you park in the spaces specifically marked for patients and visitors).

We plan to periodically survey our patients in an on-going effort to identify sources of satisfaction and dissatisfaction. Please respond honestly to our questionnaires if you receive one in the future. Your responses will never be seen by your doctor. As mentioned earlier, the purpose of these surveys is to improve the care you are receiving. Also, if you want to make comments at any time, drop them in the "Suggestion Box" in the waiting area or contact Mr. Brian Hines at 225-7590.

Thank you for sharing your feelings with us.

Sincerely,

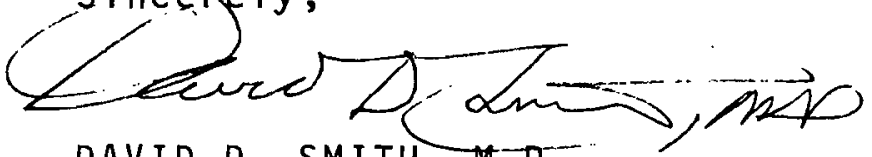

DAVID D. SMITH, M.D.

Director of Clinical Services

Department of Family Practice 
$+$

APPENDIX B

Questionnaire

$\therefore$ 
We at the Family Practice center want to know how our patients feel about their care. You can help us by honestly responding to the following statements about today's visit. Circle your responses.

Your responses will not be seen by your doctor.

1) Today my doctor made me feel foolish.

\begin{tabular}{|c|c|c|c|}
\hline $\begin{array}{l}\text { strongly } \\
\text { agree }\end{array}$ & agree & uncertain & $\begin{array}{l}\text { strongly. } \\
\text { disagree }\end{array}$ \\
\hline
\end{tabular}

2) This visit the receptionists were polite and friendly.

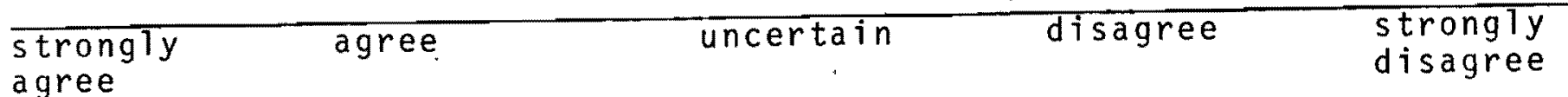

3) I had to wait too lona for my doctor today.

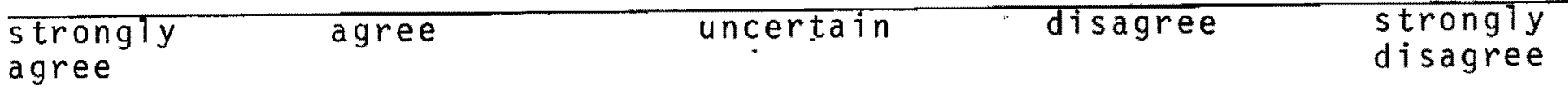

4) My "feelings were ignored-by my doctor today.

\begin{tabular}{|c|c|c|c|c|}
\hline $\begin{array}{l}\text { strongTy } \\
\text { agree }\end{array}$ & agree & uncertain & disagree & $\begin{array}{l}\text { strongly } \\
\text { disagree }\end{array}$ \\
\hline
\end{tabular}

5) Today my doctor let me tell him or her everything that was important about my condition.

\begin{tabular}{llll}
\hline strongly & agree & disagree & strongly \\
agree & & & disagree
\end{tabular}

6) This visit my doctor didn't explain very carefully what I am supposed to do.

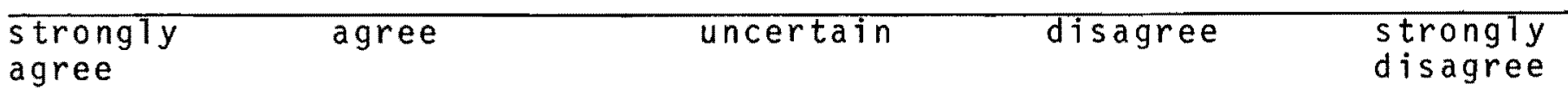

7) My doctor did the right thing for me today.

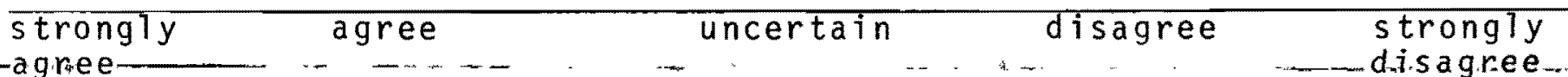

8) Today the nurses helped me understand what I am supposed to do.

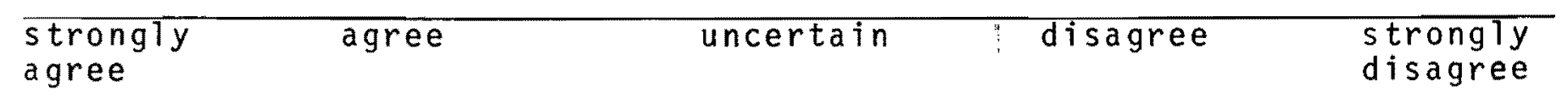

9) The nurses ignored my feelings today.

\begin{tabular}{|c|c|c|c|c|}
\hline $\begin{array}{l}\text { strongly } \\
\text { agree }\end{array}$ & agree & uncertain & disagree & $\begin{array}{l}\text { strongly } \\
\text { disagree }\end{array}$ \\
\hline
\end{tabular}

10) I feel better after my visit today.

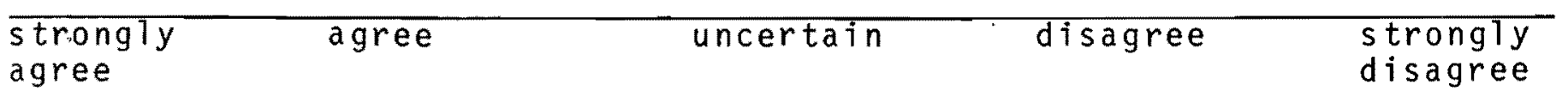

11) This visit my doctor explained my condition in such a way that I understood.

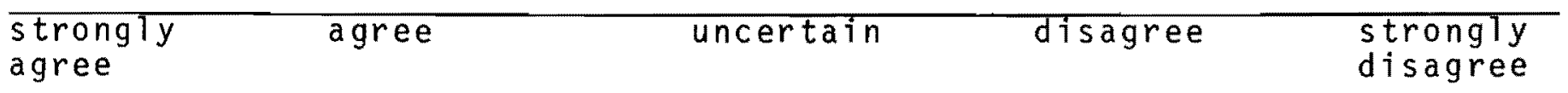

12) In general, I am satisfied with today's visit to the Family Practice Center.

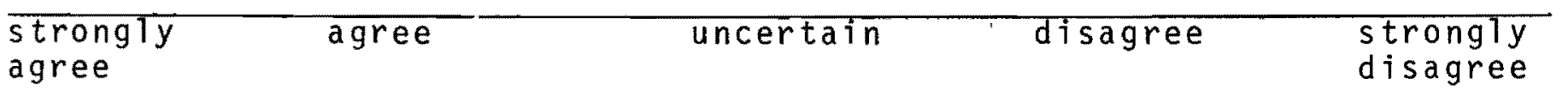

13) If you have any other comments about today's visit please note them below.

When you are finished please fold this page and drop it in the 'Suggestion Box' in the waiting room.

Thank you. 